\title{
Editorial
}

\section{Introduction to the special issue on Institutional Ethnography and Comparative Social Work}

by

Janne Paulsen Breimo

Associate Professor, $\mathrm{PhD}$

NORD University

E-mail: janne.i.breimo@nord.no

(c) (1) (2)

This work is licensed under a Creative Commons Attribution-ShareAlike 4.0 International License. 
Institutional ethnography is an approach to social inquiry developed by the Canadian sociologist Dorothy E. Smith and her co-workers, which has gained an increased amount of attention in recent years. As an alternative sociology, institutional ethnography is committed to work from- and with people's everyday experience (Smith, 2008, p. 420). As a method, it strives to discover and describe social processes that have 'generalizing effects' (DeVault \& McCoy, 2006, p.18), while as an activist approach, it is directed towards making changes in practices (Pence, 2001). Institutional ethnography and critical social work as a discipline share many characteristics. Firstly, both demonstrate a commitment to critical thinking on social processes and institutional structures. Secondly, both focus on giving a voice to people who would otherwise not have one. Thirdly, both are also dedicated to the promotion of social change and a change in power relations. For this reason, studying the practices of social work using institutional ethnography as a method of inquiry should be a good match. This is demonstrated by the articles in this special issue, which highlights the work of researchers who have applied institutional ethnography in various ways in order to investigate the various aspects of social work practices.

Anette Brunovskis' article Special rights within universal welfare: Assistance to trafficking victims in Norway reveals that the Norwegian administrative system designed to assist victims of human trafficking is actually to a large extent inaccessible to some of the least privileged members of the group the system is intended to help. Drawing on qualitative interviews with people working in central state and municipal institutions, and non-governmental organizations involved in assistance to trafficked persons in Norway, she demonstrates how special rights come into conflict with legislation governing universal welfare provision and immigration.

In Investigating the social relations of community service provision: Institutional ethnography and activism Naomi Nichols reflects on her experiences using institutional ethnography to support socially just policy, practice and organizational change in social and human service institutions in Canada. Institutional ethnography has a tradition for being activist oriented; however, Nichols argues that most researchers using this approach lately have failed to move their research into action, 
and she asks why this is the case. Analysing three projects of which she has been a part, the problem, she claims, is that in order to export research results, researchers tend to write up their findings in ways that are what she terms 'institutionally actionable', abstracted and objectified. In line with Smith (1999), Nichols advises researchers to make an effort to reconnect scholarship and activism by making sociological maps that are accessible enough to deliver on the promise of creating a sociology for people.

Ann Christin Nilsen's article In-between discourses: Early intervention and diversity in the Norwegian kindergarten sector explores two dominant discourses found in Norwegian kindergarten practices, i.e. what is called the discourse of 'early intervention' and the discourse of 'diversity'. Drawing on an observation of one professional meeting, as well as in-depth interviews of four core informants, Nilsen demonstrates how multiple discourses shape the work of the kindergarten staff. She claims that the consequence of this may be that children of different backgrounds are treated unequally. Nilsen argues that the discourses are activated when various 'categories' of children emerge, and she advises practitioners (as well as the rest of us) to be aware of how institutional discourses affect the way we classify children, and thereby possibly how they are treated.

In 'Teach, reduce, and discharge': Community nurses' textual production of 'independence' and the coordination of discharge from home care services, Lisa Watt starts out in the experiences of parents of children with diabetes, and uncovers how their experiences are shaped by the practices of the extra-local settings. In the aftermath of different reforms in the Canadian health care system, various services have been relocated from hospitals to community-based services. Watts demonstrates how this shift has left much of the care responsibilities on the children with diabetes themselves and their parents, mostly due to the textual production of the category of 'independence'.

In the final article Exploring the social relations of Roma employability: The case of rural segregated communities in Romania, the authors Loreni Elena Baciu, Melinda Dinca, Theofild Lazar and Johans Tveit Sandvin report from a research project on the barriers of including Roma individuals in the Romanian labour market. Starting with 
the experiences of Roma individuals themselves, the article demonstrates how their experience are shaped and maintained by translocal relations of administration and governance. These relations distance the Roma individuals from the formal labour market in segregated rural communities.

In sum, these contributions present a varied picture of empirical studies informed and inspired by institutional ethnography as a sociology for people, and a method of inquiry useful for exploring and analysing issues related to the discipline of social work and its practices.

DeVault, M., \& McCoy, L. (2006). Institutional ethnography: using interviews to investigate ruling relations. In Dorothy E. Smith (Ed.), Institutional ethnography as practice. Lanham (US): Rowman \& Littlefield Publishers, Inc.

Pence, E. (1999). Safety for battered women in a textually mediated legal system. Studies in Cultures, Organizations and Societies. 7(2), 199- 229.

Smith, D. E. (1999). Writing the social: Critique, theory, and investigations. Toronto, ON: University of Toronto Press.

Smith, D. E. (2008). From the 14 level sidewalk. Writing Sociology at Ground Level. Sociological Inquiry. 78(3), 214-422. 